\title{
Bacteriotherapy with Streptococcus salivarius 24SMB and Streptococcus oralis 89a nasal spray for preventing recurrent acute otitis media in children: a real-life clinical experience
}

This article was published in the following Dove Press journal:

International Journal of General Medicine

19 June 2017

Number of times this article has been viewed

Ignazio La Mantia

Attilio Varricchio

Giorgio Ciprandi

Associazione Italiana Vie Aeree Superiori, Naples, Italy
Correspondence: Giorgio Ciprandi

Via Boselli 5, 16I46 Genoa, Italy

Tel +391035338120

Email gio.cip@libero.it
Abstract: Recurrence of acute otitis media (RAOM) is a relevant issue in the clinical practice. "Bacteriotherapy" has been proposed as an option in children with RAOM. Streptococcus salivarius $24 \mathrm{SMB}$ nasal spray has been previously demonstrated to reduce the risk of acute otitis media (AOM) in otitis-prone children. The current retrospective and observational study aimed to confirm this outcome in a real-life setting, such as the common pediatric practice. Group A (108 children) served as control; group B (159 children) was treated with S. salivarius 24SMB and Streptococcus oralis 89a nasal spray after the first AOM episode. Active treatment consisted of 3 monthly courses: 2 puffs per nostril twice/day for a week. Group B showed a significant reduction of AOM episodes in comparison with group A $(p<0.0001)$. Notably, all actively treated children with the highest $\mathrm{AOM}$ recurrence had a reduction of recurrence, whereas only $50 \%$ of the control group children had reduced RAOM $(p<0.0001)$. Also, severity grade of AOM significantly diminished after the preventive bacteriotherapy $(p<0.0001)$. In conclusion, the current retrospective and observational study demonstrated that S. salivarius $24 \mathrm{SMB}$ and $S$. oralis 89a nasal spray could be effective in the prevention of RAOM in a real-life setting.

Keywords: recurrent acute otitis media, bacteriotherapy, Streptococcus salivarius 24SMB, Streptococcus oralis 89 a, nasal spray, children

\section{Introduction}

Acute otitis media (AOM) is an ear disorder defined by signs and symptoms of acute infection. ${ }^{1} \mathrm{AOM}$ is the most common bacterial infection in children. ${ }^{2-6}$ Consequently, $\mathrm{AOM}$ is the most common reason for antibiotic prescription in the pediatric age. ${ }^{7,8}$ Almost all children may experience at least one episode of AOM during the childhood. Therefore, the burden of AOM is relevant concerning both the direct (healthcare expense) and indirect cost (loss of school and work days) and the impact on quality of life of children and their parents (mainly concerning sleep and pain). Moreover, antibiotic overuse is the main cause for the increase of multidrug-resistant microbes and for the occurrence of adverse reactions. ${ }^{9,10}$ For these reasons, several guidelines on AOM management were performed to optimize the therapeutic strategy. ${ }^{2-6}$ However, these guidelines are frequently disregarded in the clinical practice. For example, an Italian experience, conducted before and after the Italian guidelines publication, showed that the antibiotic prescription for AOM was substantially unchanged (from $82 \%$ to $81 \%$ ). ${ }^{11}$

However, some children with AOM tend to be otitis-prone, such as to have frequent recurrence of AOM (RAOM). International guidelines on AOM management define 
RAOM when at least 3 episodes occur in the preceding 6 months or at least 4 episodes in the preceding year. ${ }^{2-6}$ So, the potential prevention of RAOM has raised a profound interest in the clinical practice. ${ }^{12-16}$ In fact, preventing RAOM might significantly affect the risk of complications, medical costs, and social and family impact.

Different options have been proposed, but the outcomes were conflicting and consensus is not still definitive. An interesting way has been highlighted by the study of oral microbiome. ${ }^{15,16}$ The physiological nasopharyngeal microbiome does inhibit the growth of local pathogens. ${ }^{17}$ So, that the administration of "good" bacteria could exert preventive effects on infections. ${ }^{18,19}$ In this regard, probiotics were administered for preventing AOM both orally ${ }^{20}$ and as nasal spray, ${ }^{21,22}$ but with inconsistent findings. Some years ago, an $\alpha$-hemolytic strain, obtained from healthy children (Streptococcus salivarius 24SMB), was identified. ${ }^{23}$ Later, its capability to colonize upper airways has been confirmed and its safety and tolerability when administered by nasal spray in healthy subjects. ${ }^{24}$ Consequently, a first study aimed to demonstrate its capability to reduce the risk of new episodes of AOM in otitis-prone children. ${ }^{25}$ The results were promising, so we retrospectively evaluated its use together with Streptococcus oralis 89a in a real-life setting, such as in the common practice by family pediatricians in Catania (Sicily). Therefore, the aim of the current study was to evaluate the possible preventive effect of $S$. salivarius $24 \mathrm{SMB}$ and $S$. oralis 89 a nasal spray in children suffering from RAOM.

\section{Materials and methods Study design}

This observational study was retrospectively performed. The study conformed to the Helsinki Declaration and was approved by the independent Review Board of the Associazione Italiana Vie Aeree Superiori. Primary endpoint was the assessment of the AOM episodes number during a "cool season", such as the period characterized by the AOM occurrence. As a matter of fact, children were first evaluated between November 2014 and March 2015 (screening period) to select subjects with RAOM, such as at least 3 episodes of AOM. The clinical setting was the office of 45 family pediatricians in the Catania area (Sicily, Italy).

Inclusion criteria were as follows: 1) age ranging between 3 and 10 years, 2) both genders, 3) diagnosis of RAOM documented during the screening period, and 4) written informed consent by parents. Exclusion criteria were as follows: 1) severe allergic symptoms (such as able to interfere with the assessment of treatments), 2) congenital or acquired immunodeficiency, 3) craniofacial abnormalities, 4) sleep apnea, 5) Down syndrome, 6) chronic metabolic disorders, and 7) interfering medications.

The diagnosis of AOM was made according to validated criteria defined by the Italian ${ }^{2}$ and American ${ }^{4}$ guidelines, namely signs and symptoms of acute infection, including fever, earache, irritability, bulging of tympanic membrane at otoscopic evaluation, and otorrhea (if present). AOM severity was assessed according to the Le Saux protocol. ${ }^{26}$

Then, the patients were reevaluated at the first episode of AOM during the period between November 2015 and March 2016. Randomly, the children were subdivided in two groups: 1) to be treated only when an AOM episode occurred (group A, such as the control group) or 2) prescribing bacteriotherapy with $S$. salivarius $24 \mathrm{SMB}$ and $S$. oralis 89 a nasal spray as preventive therapy (group B, such as the active group).

Children belonging to group B were treated (after AOM diagnosis), following the Italian guidelines for AOM, with amoxicillin ( $50 \mathrm{mg} / \mathrm{kg} / \mathrm{day}, 2-3$ doses) for mild-to-moderate symptoms or amoxicillin + clavulanic acid (80-90 mg/kg/ day, 2-3 doses) for severe symptoms for 7 days. Antibiotic course was also useful for favoring colonization of $S$. salivarius $24 \mathrm{SMB}$ and $S$ oralis $89 \mathrm{a}$ and reducing the competing nasopharyngeal bacteria, as previously reported.24,25 After 5 days, preventive treatment with a commercially available class IIa medical device, nasal spray containing $S$. salivarius 24SMB and $S$. oralis 89 a (Rinogermina nasal spray, DMG, Rome, Italy), was started. It was administered as 2 puffs for nostril twice/day for 7 days. The suspension consisted of a minimum of $10^{9}$ colony-forming units per dose. This course was administered for 3 consecutive months.

Children of group A were treated only during the AOM episodes prescribing antibiotics when necessary according to the Italian guidelines or with analgesic/anti-inflammatory drugs once as needed. ${ }^{2}$ Later, children were visited after each new AOM episode during the study period. During every visit, a complete clinical examination and an otoscopic examination were performed.

The primary outcome was the number of AOM episodes during the study period (November to March). The secondary outcome was the effect of bacteriotherapy on the severity grade of AOM episodes assessed according to the Le Saux grading. ${ }^{26}$ Adherence to treatment was evaluated by the number of administered doses recorded in a diary by the caregivers. Safety and tolerability were assessed recording adverse events. 


\section{Statistical analysis}

Comparison of categorical variables was made using chisquare test and post hoc Bonferroni's test; a $p$-value $<0.05$ was considered significant. Statistical analyses were done with Stata software (StataCorp LP, StataCorp. 2013, Stata Statistical Software: Release 13, College Station, TX, USA).

\section{Results}

Globally, 267 children (155 males, 112 females; mean age 4.9 years, age range $3-8$ years) were evaluated. Group A consisted of 108 children (mean age $4.6 \pm 1.3$ years) and group B of 159 children (mean age $4.9 \pm 1.2$ years) (Table 1). The two groups were homogeneous concerning both age and gender.

In group B, the first AOM episode occurred in November (34 subjects), December ( 50 subjects), or January (75 subjects).

Table I Clinical outcomes

\begin{tabular}{llll}
\hline & Subjects & Unchanged & p-value \\
\hline $\begin{array}{l}\text { Groups, n (\%) } \\
\text { Group A }\end{array}$ & 108 & $74(68.5)$ & \\
Group B & 159 & $15(9.4)$ & $<0.000$ I \\
Right ear, n (\%) & & & \\
Group AI & 78 & $59(75.6)$ & \\
Group B I & 101 & $15(14.9)$ & $<0.000$ I \\
Left ear, n (\%) & & & \\
Group A2 & 30 & $15(50)$ & \\
Group B2 & 58 & $0(0)$ & $<0.000$ I \\
\hline
\end{tabular}

Children were also subdivided in two subgroups according to the number of AOM episodes that occurred during the screening period: 3 episodes (group A1 and group B1) or $>4$ episodes (group A2 and group B2), as reported in Table 1.

In the group A, 74 (68.5\%) out of 108 children showed the same number of AOM episodes. Analyzing the two subgroups, 59 (75.6\%) out of 78 children in group A1 and 15 (50\%) out of 30 in group $\mathrm{A} 2$ remained unchanged concerning the number of AOM episodes.

In the group B, 15 (9.4\%) out of 159 children showed the same number of AOM episodes. Analyzing the two subgroups, 15 (14.9\%) out of 101 children in group B1 and nobody $(0 \%)$ out of 58 in group B2 remained unchanged concerning the number of AOM episodes.

The intergroup comparison showed a significant difference between all groups ( $p<0.0001$ for all). In particular, in group A2, all the 15 children with a reduction of AOM episodes had two AOM episodes alone (notably 6 were allergic to house dust mites), whereas in group B2, 36 children had one single AOM episode, 15 had two AOM episodes, and 7 had three AOM episodes (notably all of them were allergic to house dust mites), as reported in Figure 1.

About the severity grade of AOM episodes in group B, scored according to Le Saux criteria, ${ }^{26}$ at the first episode 78 children (49\%) had mild severity, 58 (36\%) moderate, and 23 (15\%) severe AOM. In the successive episodes, 96 (81\%) children had mild AOM and 22 (19\%) moderate AOM;

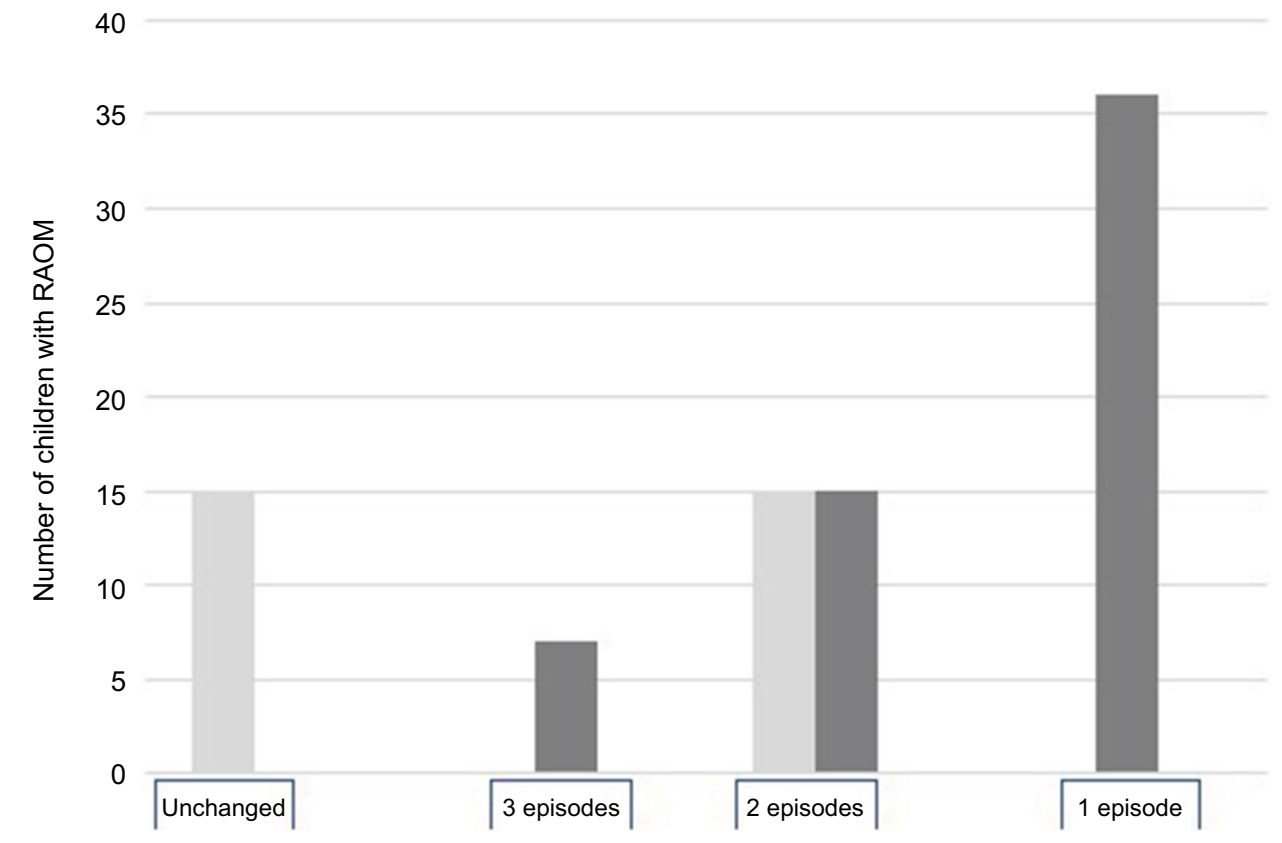

Figure I Number of children with recurrence of acute otitis media in group A2 (light grey) and in group B2 (dark gray) who experienced unchanged, 3, 2, or I, number of acute otitis media episodes.

Abbreviation: RAOM, recurrence of acute otitis media. 
Table 2 AOM clinical severity

\begin{tabular}{|c|c|c|}
\hline & $\begin{array}{l}\text { Severity } \\
\text { grade }\end{array}$ & $P$-value \\
\hline \multicolumn{3}{|c|}{ First episode, n (\%) } \\
\hline Mild & 78 (49) & \\
\hline Moderate & $58(36)$ & \\
\hline Severe & $23(15)$ & \\
\hline \multicolumn{3}{|c|}{ Successive episodes, n (\%) } \\
\hline \multirow[t]{2}{*}{ Mild } & $96(81)$ & $p<0.0001$ \\
\hline & & post hoc Bonferroni's test \\
\hline \multirow[t]{2}{*}{ Moderate } & $22(19)$ & Mild vs moderate $p<0.000 \mathrm{I}$ \\
\hline & & Mild vs severe $p<0.0001$ \\
\hline Severe & $0(0)$ & Moderate vs severe $p=0.0136$ \\
\hline
\end{tabular}

Abbreviation: AOM, acute otitis media.

notably, no child had severe AOM (Table 2). These findings were highly significant $(p<0.0001)$.

In addition, in group B1, antibiotic was prescribed in only 15 out of 35 children with one AOM and in 10 out of 25 children with two AOM episodes. All treatments were well tolerated, and no clinically relevant side effect was observed.

\section{Discussion}

RAOM represents an intriguing challenge for both the ENT specialist and the pediatrician. The AOM diagnosis requires adequate procedure and precise differential diagnosis, mainly concerning the otitis media with effusion. Moreover, AOM therapy is controversial as many guidelines suggest a watchful waiting for mild-to-moderate episodes in children aged $>2$ years. However, in the clinical practice, antibiotics are frequently prescribed, ignoring guidelines precepts. ${ }^{11}$ In addition, prevention of RAOM is even more debated. At present, there is no convincing evidence about the proposed treatments both conventional and not.

Previously, it was reported that AOM tend to more easily develop in subjects presenting particular pattern of microbiota. ${ }^{18,19}$ So, "bacteriotherapy", such as the use of "good" bacteria, may be a promising way. In fact, the rationale is based on the demonstration that some nonpathogenic strains may protect from bacterial infections. ${ }^{12-15}$

The current findings showed that $S$. salivarius $24 \mathrm{SMB}$ and $S$. oralis 89 a nasal spray was able to induce a clinically relevant reduction of AOM recurrence in a high percentage of patients with RAOM. In particular, all children with the highest number of RAOM reduced the number of recurrence. In addition, children treated with the current bacteriotherapy experienced less severe AOM episodes.

Therefore, the current study, conducted in a real-life setting, provides preliminary evidence that $S$. salivarius $24 \mathrm{SMB}$ and $S$. oralis 89 a nasal spray may be a reliable option in RAOM prevention. Of note, no side effects were reported, so the compound was safe and well tolerated by all treated children.

Consequently, the present experience is partially consistent with the previous study conducted in an experimental setting. ${ }^{25}$ Marchisio et al demonstrated that $S$. salivarius $24 \mathrm{SMB}$ nasal spray was able to significantly reduce the numbers of AOM in children colonized by this strain in comparison with non-colonized children. ${ }^{25}$ Actually, $>40 \%$ of the treated and colonized children did not experience any AOM episodes. Noteworthy, only long-term antibiotic prophylaxis may give better outcomes, but of course this strategy may be burdened by relevant adverse events. In addition, that study ${ }^{25}$ evidenced that $S$. salivarius $24 \mathrm{SMB}$ nasal spray was safe and well tolerated, confirming previous reports. ${ }^{24,25}$ This issue is relevant, also, in the light of the fact that long antibiotic duration is more effective than short-term (5 days), with no increase in the rate of adverse events. ${ }^{27}$ Thus, it has been suggested that 10 days of amoxicillin-clavulanate for children $>2$ years of age with AOM seems to be a reasonable option. ${ }^{28}$ Therefore, to save antibiotic long-term use may be a further advantage. However, the present study provided more relevant outcomes than the previous one conducted by Marchisio et al. A possible explanation might be related to the use of the combination of $S$. salivarius $24 \mathrm{SMB}$ with $S$. oralis $89 \mathrm{a}$. Hence, the two strains might have synergic effects.

It is also to note that the considered period (November to March) might seem short, but the Sicily climate is characterized by a temperate winter season (Catania is at $37^{\circ} \mathrm{N}$ ). Therefore, the period of AOM occurrence is usually limited to November to March.

However, the present study has some limitations: 1) to be an open and retrospective study, 2) to be without a true placebo group, 3) to be based only on clinical outcomes without cultural investigations, and 4) the random allocation was arbitrarily decided by the doctor. However, the study was performed in a large group of children and in a real-life setting, so the outcomes could be reasonably considered convincing. However, further studies should be conducted to correctly define the unmet needs.

\section{Conclusion}

In conclusion, the current retrospective and observational study demonstrated that $S$. salivarius $24 \mathrm{SMB}$ and $S$. oralis 89a nasal spray could be effective in the prevention of RAOM in the common clinical practice.

\section{Disclosure}

The authors report no conflicts of interest in this work. 


\section{References}

1. Gisselson-Solen M. Acute otitis media in children - current treatment and prevention. Curr Infect Dis Rep. 2015;17(5):22.

2. Marchisio P, Bellussi L, Di Mauro G, et al. Acute otitis media: from diagnosis to prevention. Summary of the Italian guideline. Int J Ped Otorhinolaryngol. 2010;74(11):1209-1216.

3. Heidemann CH, Lous J, Berg J, et al. Danish guidelines on management of otitis media in preschool children. Int J Ped Otorhinolaryng. 2016;87(3):154-163.

4. Lieberthal AS, Carroll AE, Chonmaitree T, et al. The diagnosis and management of acute otitis media. Pediatrics. 2013;131(3): e964-e999.

5. Siddiq S, Grainger J. The diagnosis and management of acute otitis media: American Academy of Pediatrics Guidelines 2013. Arch Dis Child Educ Pract Ed. 2015;100(4):193-197.

6. Kitamura K, Iino Y, Kamide Y, et al. Clinical practice guidelines for the diagnosis and management of acute otitis media (AOM) in children in Japan-2013 update. Auris Nasus Larynx. 2015;42(2):99-106.

7. Rettig E, Tunkel DE. Contemporary concepts in management of acute otitis media in children. Otolaringol North Am. 2014;47(5):651-672.

8. Tamir SO, Shemesh S, Oron Y, Marom T. Acute otitis media guidelines in selected developed and developing countries: uniformity and diversity. Arch Dis Child. 2017;102(5):450-457.

9. Morris PS, Leach AJ. Antibiotics for persistent nasal discharge (rhinosinusitis) in children. Cochrane Database Syst Rev. 2008;2:CD001094.

10. Molstad S, Erntell M, Hanberger H, et al. Sustained reduction of antibiotic use and low bacterial resistance: 10-year follow-up of the Swedish Strama programme. Lancet Infect Dis. 2008;8(5):125-132.

11. Palma S, Rosafio C, Del Giovane C, et al. The impact of Italian guidelines on antibiotic prescription practices for acute otitis media in a pediatric emergency setting. It J Pediatr. 2015;41:37.

12. Gao Z, Kang Y, Yu J, Ren L. Human pharyngeal microbiome may play a protective role in respiratory tract infections. Genomics Proteomics Bioinformatics. 2014;12(1):144-150.

13. Marchisio P, Nazzari E, Torretta S, Esposito S, Principi N. Medical prevention of recurrent acute otitis media: an updated overview. Expert Rev Anti Infect Ther. 2014;12(5):611-620.

14. Maron T, Marchisio P, Tamir SO, Torretta S, Gavriel H, Esposito S. Complementary and alternative medicine treatment options for otitis media. Medicine. 2016;95(6):e2695.

15. Niittyen L, Piktaranta A, Korpela R. Probiotics and otitis media. Int J Ped Otorhinolaryngol. 2012;76(4):465-470.
16. Walls T, Power D, Tagg J. Bacteriocin-like inhibitory substance (BLIS) production by the normal flora of the nasopharynx: potential to protect against otitis media? J Med Microbiol. 2003;52(9):829-833.

17. Tano K, Olofsson C, Grahn-Hakansson E, Holm SE. In vitro inhibition of $S$ pneumoniae, nontypeable $H$ influenza and $M$ catharralis by alpha-hemolytic streptococci from healthy children. Int J Ped Otorhinolaryngol. 1999;47(1):49-56.

18. Brook I, Gober AE. In vitrobacterial interference in the nasopharynx of otitis media prone and non otitis media prone children. Arch Otolaryngol Head Neck Surg. 2000;126(9):1011-1013.

19. Bernstein JM, Faden HF, Dryja DM, Wactawski-Wende J. Micro-ecology of the nasopharyngeal bacterial flora in otitis-prone and non-otitis-prone children. Arch Otolaryngol. 1993;113(1):88-92.

20. Cohen R, Martin E, de La Rocque F, et al. Probiotics and prebiotics in preventing episodes of acute otitis media in high-risk children: a randomized, double-blind, placebo-controlled study. Ped Infect Dis J. 2013;32(8):810-814.

21. Tano K, Grahn-Hakansson E, Holm SE, Hellstrom S. A nasal spray with alpha-haemolytic streptococci as long term prophylaxis against recurrent otitis media. Int J Ped Otorhinolaryngol. 2002;62(1):17-23.

22. Skovbjerg S, Roos K, Holm SE, et al. Spray bacteriotherapy decreases middle ear fluid in children with secretory otitis media. Arch Dis Child. 2009;94(2):92-98.

23. Santagati M, Scillato M, Patanè F, Aiello C, Stefani S. Bacteriocinproducing oral streptococci and inhibition of respiratory pathogens. FEMS Immunol Med Microbiol. 2012;65(1):23-31.

24. Santagati M, Scillato M, Muscaridola N, Metoldo V, La Mantia I, Stefani S. Colonization, safety, and tolerability study of the Streptococcus salivarius $24 \mathrm{SMBc}$ nasal spray for its application in upper respiratory tract infections. Eur J Microbiol Infect Dis. 2015;34(10):2075-2080.

25. Marchisio P, Santagati M, Scillato M, et al. Streptococcus salivarius 24SMB administered by nasal spray for the prevention of acute media otitis in otitis-prone children. Eur J Microbiol Infect Dis. 2015;34(12):2377-2383.

26. Le Saux N, Gaboury I, Baird M, et al. A randomized, double-blind, placebo-controlled noninferiority trial of amoxicillin for clinically diagnosed acute otitis media in children 6 months to 5 years of age. CMAJ. 2005;172(3):335-341.

27. Hoberman A, Paradise JL, Rockette H, et al. Shortened antimicrobial treatment for acute otitis media in young children. NEJM. 2016;375(25):2446-2456.

28. Kenna MA. Acute otitis media - the long and the short of it. $N$ Engl J Med. 2016;375(25):2492-2493.
International Journal of General Medicine

\section{Publish your work in this journal}

The International Journal of General Medicine is an international, peer-reviewed open-access journal that focuses on general and internal medicine, pathogenesis, epidemiology, diagnosis, monitoring and treatment protocols. The journal is characterized by the rapid reporting of reviews, original research and clinical studies across all disease areas.

\section{Dovepress}

The manuscript management system is completely online and includes a very quick and fair peer-review system, which is all easy to use. Visit http://www.dovepress.com/testimonials.php to read real quotes from published authors. 